\title{
Oxidation of Benzylic Alcohols with Iodine and Lithium Carbonate in Ionic Liquid
}

\author{
Seung Bae Lee and Jong Chan Lee \\ Department of Chemistry, Chung-Ang Lniversity, Seoul 156-756, Korea. E-mail: jclee âcau ack \\ Received August 6, 2009. Accepted October 19, 2009
}

Key Words: Benzylic alcohol. Iodine. Ionic liquid. Oxidation

The oxidation of benzylic alcohols to the corresponding carbonyl compounds is a very important transformation in organic chemistry and a variety of methods have been reported. Numerous reagents have been utilized for the oxidation of benzylic alcohols. For examples transition metals complexes such as chromium(VI) complexes. 'nthenium reagents. ${ }^{2}$ and mianganese dioxide $^{3}$ are widely utilized. In addition hypervalent iodine(V) compounds such as Dess-Martin periodinate ${ }^{4}$ and $o$-iodoxy benzoic acid. ${ }^{5}$ iodosobenzene. ${ }^{6}$ and (diacetoxy iodo)benzene received much attention due to their outstanding reactivities. However. above mentioned reagents suffered from several drawbacks in terms of harsh reaction conditions. high cost. instability: high toxicity, and operational difficulty. Molecular iodine can be considered one of the most ideal oxidant in organic reactions due to its many desirable properties like low cost. safe to handle. and ready availability. However. the utilization of iodine for the oxidation of alcohols to the corresponding carbonyl compounds has been very scarce. Furthermore. due to the intrinsic low reactivity of molecular iodine compared to the other highly reactive hypervalent iodine reagents. oxidation of alcohols with molecular iodine generally required the concomitant use of activating agents. For examples. previously reported iodine induced oxidative methods had been invariably carried out in the presence of activating substances such as 2,2,6.6.-tetranetlyyl-1piperdinyloxyl (TEMPO). ${ }^{8}$ potassium iodide. ${ }^{9}$ or (diacetoxyiodo)benzene. ${ }^{\text {ji) }}$ To the best of our knowledge, successful utilization of molecular iodine in the absence of any additional promoters in the oxidation of benzylic alcohols to the corresponding carbonyl compounds has been unprecedented.

Herein, we wish to report our findings on the facile oxidation

Table 1. Oxidation of Alcohols to Aldehydes and Ketones with $\mathrm{I}_{2} / \mathrm{Li}_{2} \mathrm{CO}_{3}$

\begin{tabular}{|c|c|c|c|c|}
\hline Entry & Substrate & Product & Time $(\mathrm{h}) / \mathrm{Temp}\left({ }^{\mathrm{C}} \mathrm{C}\right)$ & Yield ${ }^{\alpha}(\%)$ \\
\hline l & $\mathrm{PhCH}_{2} \mathrm{OH}$ & $\stackrel{\mathrm{O}}{\mathrm{PhCH}}$ & $6 / 60$ & 85 \\
\hline 2 & $p-\mathrm{CH}_{3} \mathrm{C}_{3} \mathrm{H}_{4} \mathrm{CH}_{2} \mathrm{OH}$ & $p-\mathrm{CH}_{3} \mathrm{C}_{6 i} \mathrm{H}_{4} \mathrm{C}$ & $4 / 60$ & 81 \\
\hline 3 & $p-\mathrm{FC}_{6} \mathrm{H}_{4} \mathrm{CH}_{2} \mathrm{OH}$ & $p-\mathrm{FC}_{6} \mathrm{H}_{4} \mathrm{CH}$ & $4 / 60$ & 81 \\
\hline 4 & $p-\mathrm{ClC}_{6} \mathrm{H}_{4} \mathrm{CH}_{2} \mathrm{OH}$ & $p-\mathrm{ClC}_{6} \mathrm{H}_{4} \|_{\mathrm{CH}}$ & $4 / 60$ & 82 \\
\hline 5 & $p-\mathrm{BrC}_{6} \mathrm{H}_{4} \mathrm{CH}_{2} \mathrm{OH}$ & $p-\mathrm{BrC}_{6} \mathrm{H}_{4} \mathrm{CH}_{\mathrm{C}}$ & $4 / 60$ & 81 \\
\hline 6 & $p-\mathrm{CH}_{3} \mathrm{OC}_{6} \mathrm{H}_{4} \mathrm{CH}_{2} \mathrm{OH}$ & $p-\mathrm{CH}_{3} \mathrm{OC}_{6} \mathrm{H}_{4} \prod_{\mathrm{CH}}$ & $24 / 60$ & 83 \\
\hline 7 & Piperonyl alcohol & Piperonyl aldehyde & $24 / 60$ & 71 \\
\hline 8 & $\mathrm{PhCH}\left(\mathrm{CH}_{3}\right) \mathrm{OH}$ & $\stackrel{\mathrm{O}}{\mathrm{Ph}^{\prime} \mathrm{C}^{\prime} \mathrm{H}_{3}}$ & $12 / \mathrm{rt}$ & 88 \\
\hline 9 & $\mathrm{PhCH}\left(\mathrm{CH}_{2} \mathrm{CH}_{3}\right) \mathrm{OH}$ & $\prod_{\mathrm{PhCCH}_{2} \mathrm{CH}_{3}}$ & $12 / \mathrm{rtt}$ & 83 \\
\hline 10 & $p-\mathrm{ClC}{ }_{6} \mathrm{H}_{4} \mathrm{CH}\left(\mathrm{CH}_{3}\right) \mathrm{OH}$ & $p-\mathrm{ClC}_{6} \mathrm{H}_{4} \stackrel{\|}{\mathrm{C}}_{3}$ & $12 / \mathrm{rtt}$ & 87 \\
\hline 11 & $\mathrm{PhCH}(\mathrm{CN}) \mathrm{OH}$ & $\prod_{\mathrm{PhCCN}}$ & $12 / \mathrm{rt}$ & 81 \\
\hline 12 & $(\mathrm{Pl}) \times \mathrm{CHOH}$ & $(\mathrm{Ph})_{2} \mathrm{C}=\mathrm{O}$ & $12 / \mathrm{rt}$ & 84 \\
\hline $1 \hat{3}$ & $p-\mathrm{CH}_{3} \mathrm{OC}_{6} \mathrm{H}_{4} \mathrm{CH}\left(\mathrm{CH}_{3}\right) \mathrm{OH}$ & 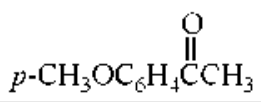 & $12 / \mathrm{rt}$ & 81 \\
\hline
\end{tabular}


of benzylic alcohols using $\mathrm{I}_{2} / \mathrm{Li}_{2} \mathrm{CO}_{3}$ in ionic liquid as a useful oxidizing system for the oxidation of benzylic alcohols. Thus. reaction of benzyl alcohol and iodine ( 1.5 equiv) at $60^{\circ} \mathrm{C}$ for $6 \mathrm{~h}$ in the presence of lithium carbonate (1.0 equiv) in 1-buty l3-methylimidazolium tetrafluoroborate. [bmim]BF 4 , exclusively yielded the benzaldelyde in $85 \%$. Replacement of $\mathrm{Li}_{2} \mathrm{CO}_{3}$ by other bases such as $\mathrm{K}_{2} \mathrm{CO}_{3}$. $\mathrm{Et}_{3} \mathrm{~N}$. and 2.6-lutidine gave always inferior yields of desired products. At the present reaction conditions, various primary benzylic alcohols underwent smooth

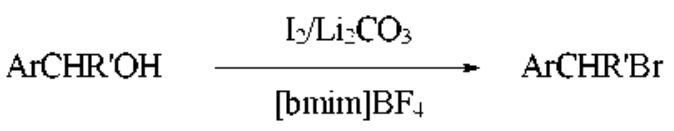

oxidation to provide highyields of the corresponding aldelydes as summarized in Table 1. Over-oxidized products were not detected at the present reaction conditions. Next. our attention was directed towards oxidation of secondary alcohols. As exemplified in Table 1. secondary benzylic alcohols (entries 8-13) reacted efficiently giving high yields of ketones. Interestingly. in cases of oxidation of secondary benzylic alcohols. strong temperature dependence of selectivity of reactions were found with the highest at room temperature and somewhat lowered yields were obtained at increased temperatures. At the temperature of $60^{\circ} \mathrm{C}$ complicated product mixtures were obtained. Electrondonating and withdrawing substituent in aromatic rings had relatively minor influence on the outcome of the oxidation of substituted benzylic alcohols. In all the attempted examples. our conditions were highly selective and efficient. and no over oxidation products were detected. This appears to be the first example of the oxidation of benzylic alcohols as performed by only molecular iodine without any additional activation reagent.

In conclusion. we have demonstrated a simple and effective transition metal-free protocol for the oxidation of benzy lic alcohols to the corresponding aldellydes and ketones. The simple procedure together with use of readily available. safe to use. and inexpensive molecular iodine should make present protocol an important alternative to other classical methods.

\section{Experimental Section}

The 1-butyl-3-methy limidazolium tetrafluoroborate, [bmim] $\mathrm{BF}_{4}$. was obtained from Aldrich.). Thin layer chromatography was performed on Merck silica gel $60 \mathrm{~F}-254$ plates $(0.25 \mathrm{~mm})$. Merck silica gel 60 (230 - 400 mesh) was used for flash column chromatograpliy.

General procedure. Benzy lic alcohol $(1.0 \mathrm{mmol})$ was added to a well-stirred mixture of iodine $(0.38 \mathrm{lg} .1 .5 \mathrm{mmol})$ and lithiun carbonate $(0.073 \mathrm{~g}, 1.0 \mathrm{mmol})$ in solution of [bmim]BF ( $\mathrm{l} \mathrm{mL}$ ). The mixture was stirred at $60^{\circ} \mathrm{C}$ over $6 \mathrm{~h}$. On completion of the reaction. the nuxture was dissolved in dichloromethane $(40 \mathrm{~mL})$ and washed with $5 \%$ sodium thiosulfate $(20 \mathrm{~mL})$. The organic layer was separated and dried over $\mathrm{MgSO}_{4}$ and evaporated under reduced pressure. The residue was purified by flash column chromatography (EtOAc: Hexane = $1: 3$ ) on silica gel to obtain pure carbonyl compounds.

Aclonowledgments. This research was supported by the Chung-Ang University Research Grants in 2009

\section{References}

1. Haịpour, A. R.: Mallakpour, S. E.; Khoee, S. Smlet $2000,740$.

2. Denmark, S. E.; Cramer, C. J.; Stemberg. J. A. Helv Chim. Acto $1986,69,1971$

3. Uchiyama, M.; Kimura, Y:; Ohta, A. Tetrohedron Lett. 2000, 10013 .

4. Dess, D. B.: Martin, I. C. J. Am. Chem. Soc. 1991, 133, 7277.

5. Ozanne, A.; Pouysegu, L.; Deoemet, D.; Francois, B.; Quideau, S. Org. Lett. 2003, $5,2903$.

6. Yakoo, T.; Matsumoto, K.; Oshima, K. Chent Lett. 1993, 571.

7. Narakasa, K.; Morikawa, A.; Siago, K.: Mukuiyama, T. Bull. Chem. Soc. Jpm 1999. 55.2773.

8. Miller, R. A.; Hoemner, R. P. Oig. Lett. 2003, 5, 285.

9. Gogoi, P. Konwar, D. Org. Bionol. Chent $2005,3,3473$.

10. Karade, N. N.; Tiwari, G. B.; Huple, D. B. Symlent 2005, 2039. 